\title{
RESEARCH AND RELIABILITY ANALYSIS OF DOUBLE BRIDGE CRANE CONTROL SYSTEM
}

\author{
Qi XIE ${ }^{1}$, Hao WEN ${ }^{2}$, Quanwei WANG ${ }^{3}$ \\ 1, 2, 3 Taiyuan University of Science and Technology, Taiyuan 030024 China \\ e-mail: xieqisky00@yeah.net
}

\begin{abstract}
In order to improve the utilization efficiency of the bridge crane and reduce the labor intensity of the staff, the original control system of bridge crane is deeply studied, combined with the research status of bridge crane control system at home and abroad, the control method of centralized monitoring of double bridge crane is proposed. The new positioning method is used to make the positioning more accurate. The industrial control computer can be used to configure the human-machine interface, and the structure of the industrial control computer backplane plus card is beneficial to the expansion of the system. The monitoring network is built by wireless digital radio, and the wireless way makes system maintenance and expansion simple and convenient. On this basis, the development platform is used to develop the design monitoring program, and the corresponding control program is written to meet the system requirements. After completing the overall design of the system, the fault tree analysis method is applied to analyze the reliability of the double bridge crane control system. According to the composition of the system, the fault tree analysis diagram is established, the Boolean algebra function is used to find the minimum cut set of the system, and the reliability of the double bridge crane control system is qualitatively and quantitatively analyzed according to the relevant data. The designed system finally realizes remote monitoring through the actual application in the field, and the control effect is good, which can meet the requirements of automatic control.
\end{abstract}

Keywords: Bridge crane; Centralized monitoring; Reliability analysis.

\section{Introduction}

With the rapid development of modern industry and the full utilization of new technologies and new processes, social productivity has leapt to a new level (Fan et al., 2017; Hossain et al., 2017).

As a production and transportation equipment, bridge cranes play an important role in the metallurgy, logistics, mining, port and other industries. In the new century and new era, when global enterprises are occupying the highest efficiency of production, the automation of production has become the goal pursued by enterprises (Kulka et al., 2016; Molaei et al., 2016; Zhu et al., 2017). The automation of bridge cranes undoubtedly plays a decisive role in the process of enterprise automation. In order to achieve automation of the bridge crane, in addition to improvements in the control elements, the improvement of the control method is also an important method (Prabaharan et al., 2017; Li et al., 2017).

As a current popular control method, centralized monitoring has the advantages of direct, rapid, and easy overall coordination, which provides convenience for enterprise production scheduling and management. It can not only greatly improve the processing quality, but also improve labour productivity and reduce the labour intensity of workers. It is an important step to automatically control the development from single machine automation to multi-machine automation to achieve full automation. More importantly, the use of development monitoring programs in monitoring allows operators to more intuitively observe the operational status of bridge cranes (Li et al., 2017; Xu et al., 2016).

In the process of achieving centralized monitoring, multi-unit network has become a key technology. There are many ways of the system network, and wireless methods are receiving more and more attention. As a data transmission device, the wireless data transmission station has convenient connection, reliable and convenient data transmission, simple maintenance, it can be applied in harsh environments and saves the cost of wiring. It has been widely used in the field of industrial control (Chen et al., 2017; Ramli et al., 2017).

For centralized monitoring, the application of wireless data transmission stations makes it more convenient to expand (Dragović et al., 2017; Jalaludin et al., 2017).

As a production and transportation equipment, bridge cranes are widely used in metallurgy, mining, 
machinery and equipment manufacturing, etc., and their reliability is of great significance to factory enterprises. With the rapid development of the crane industry, the corresponding safety accidents have also increased relatively. This has caused the national safety supervision department to attach great importance to the reliability of the crane.

Therefore, the reliability analysis of the bridge crane becomes very necessary (Aziz et al., 2017; Kulka et al., 2018).

\section{Methodology \\ 2.1 Hardware design of double bridge crane control system}

The design of this system is based on the control system of two bridge cranes in the finished product warehouse of Tianjin Taigang Tianguan Stainless Steel Co., Ltd. These two bridge cranes are mainly used for handling and discharging steel coils into and out of the warehouse. The handling tasks are heavy and the workload is also heavy. Through the transformation of the original system, centralized monitoring of the two bridge cranes can be realized, which facilitates centralized dispatch management. It can increase production efficiency and reduce the labour intensity of operators.

The double bridge crane control system is based on the original control system. In the original system, two bridge cranes can operate independently and can fulfil the operation requirements. But the two cranes operate independently, each bridge crane needs to be manned, and production scheduling is also lacking in management. In order to realize realtime monitoring and centralized management of the two cranes, a central control room is established on the ground of the workshop, and the operating status and operating parameters of the two cranes are transmitted to the central control room through the wireless data transmission radio. Two bridge cranes can be monitored through the central control room.

The control system can be divided into three parts from the hardware structure. The first part is the bridge crane subsystem. The second part is a wireless transmission system composed of digital radio and FM signals. The third part is the central control room monitoring system.

The central control room monitoring system is built on the workshop floor, which is mainly composed of industrial control computer and wireless data transmission radio. The industrial control computer can be provided separately or directly use the central control room to manage the computer. The central control room staff can send information such as the shipping list to the two bridge crane controllers, the controller can ship according to the list, and can also control the two bridge cranes in the central control room to complete the cargo lifting.
The main functions of the central control room monitoring system are the establishment of communication channels, data transmission and reception, data processing, parameter and status query, and record of workshop inventory.

The bridge crane subsystem is built on the bridge crane and is the motion control system of the bridge crane, which moves with the movement of the bridge crane.

The original system of the system was developed by Dalian Crane Co., Ltd. The original system has an independent control system that can operate independently, but it can't meet the requirements of automatic control. In order to save costs, the original system is directly modified, and industrial control computers, position sensors, etc. are added to the original system.

Accurate positioning of the bridge crane can be realized by adding laser range finder, encoder, bar coder and other sensors in the lateral, longitudinal and vertical directions of the bridge crane in combination with the on-site installation conditions.

The entire system measures the position information of the bridge crane through the position sensor and submits it to the industrial computer for calculation or configuration. For the control of the bridge crane, the industrial control machine issues a control command to the inverter through the bus. After receiving the command, the inverter controls the rotation of the bridge crane cart and the hoist mechanism motor to control the operation of the crane.

In the wireless communication system, the communication module transmits the data to the FM signal and transmits it via the antenna, which is not affected by the geographical location, and saves the trouble of wiring, saves cost, and facilitates the expansion of the communication network.

The communication module used in this system is the latest digital radio station developed by Jing Company.

The wireless data transmission station has an antenna interface, a programming interface and a female interface. The antenna interface is connected to the coaxial cable and finally connected to the antenna for receiving and transmitting the FM signal.

The programming interface and dedicated programmer connection can be used to program the digital radio station and set some parameters.

The female interface can be used as an analogy interface or as a standard serial communication port. In this design, it is used as a standard serial communication port, and can be directly connected to the serial port of the computer through a serial cable. 
The definition of each pin is shown in Table 1.

Table 1. Serial pin definition

\begin{tabular}{|c|c|l|}
\hline $\begin{array}{c}\text { Serial pin } \\
\text { number }\end{array}$ & $\begin{array}{c}\text { Standard } \\
\text { definition }\end{array}$ & \multicolumn{1}{|c|}{ Function } \\
\hline 1 & CD & Carrier detect signal output \\
\hline 2 & RXD (A) & $\begin{array}{l}\text { MODEM demodulation data } \\
\text { signal output }\end{array}$ \\
\hline 3 & TXD (B) & $\begin{array}{l}\text { Transmit data signal sent to } \\
\text { MODEM for modulation }\end{array}$ \\
\hline 4 & DTR & Number/word switching \\
\hline 5 & GND & Ground \\
\hline 6 & Vcc & Power output \\
\hline 7 & RTS & Send request \\
\hline 8 & CTS/AI & $\begin{array}{l}\text { Reserve multi-function serial } \\
\text { port pin }\end{array}$ \\
\hline 9 & SM/A2 & $\begin{array}{l}\text { Reserve multi-function serial } \\
\text { port pin }\end{array}$ \\
\hline
\end{tabular}

In this control system, because the central control room is to monitor two bridge cranes through the radio station, and the communication distance is short, the point-to-multipoint communication mode is adopted. The network structure of the point-tomultipoint communication system is generally a star or tree structure. There are generally central stations and subscriber stations in the system, and relay stations in some systems.

The central station is typically an operator station for monitoring the entire network system.

The subscriber station generally connects to the user equipment to provide communication services for the equipment.

The relay station is an intermediate station for acknowledging the problem that the FM signal will be attenuated during long-distance transmission. In this system, because the wireless communication distance is short, the FM signal attenuation is small, and the communication effect is not affected. There is no relay station.

At each control point, the module and computer are connected through the serial port. The connection is shown in Figure 1.

The main pins are RXD, TXD and GND.

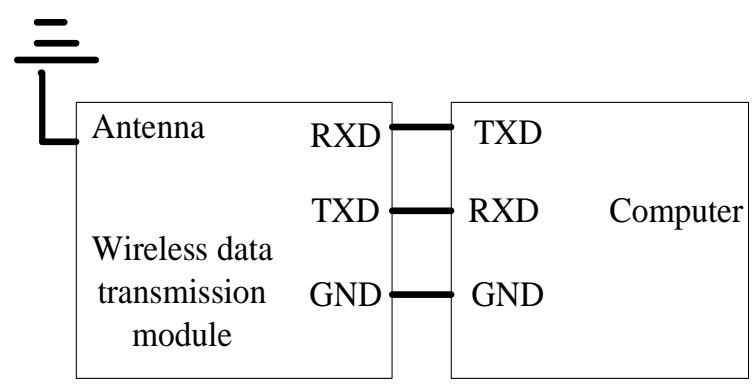

Figure1: Serial port connection diagram

The standard serial communication port interface of the digital radio station can be easily connected to the serial port of the computer without the need for third-party equipment.
Its initial settings are the same as the serial port settings.

When the bridge crane subsystem sends data to the central control room system, the bridge crane subsystem radio receives the digital signal from the serial port, and the transceiver of the radio modulates the signal into a $230 \mathrm{MHz}$ FM signal and then transmits it from the antenna.

The transceiver of the radio receives the FM signal, demodulates it into a digital signal, and transmits it to the central control room computer via the serial port. This completes the one-way data transfer. Similarly, when the central control room sends a signal to the crane subsystem, the digital signal and the FM signal are also converted and connected to the devices at both ends via the serial port.

This can complete the two-way sending and receiving of data.

\subsection{Software design of double bridge crane control system}

The control system software part mainly includes three parts, monitoring software program design, communication software program design and PLC program design.

The monitoring software program and the communication software program are written by the Visual Basic. The PLC program is written on the step 7 platform of Siemens.

PLC program

The programming of the PLC program is based on the original bridge crane program.

The original system is mainly the manual control program of the operating handle.

By controlling the operation handle to output 4$20 \mathrm{~mA}$ signal to the analog signal input module of the PLC, after the data conversion and corresponding calculation of the PLC, the output of the obtained control command is sent to the inverter, and the inverter controls the rotation of the motor to drive wheel rotation or roller rotation connected to the motor.

After the application of the industrial computer, the corresponding automatic control program needs to be written.

At the same time, the original manual control program is retained, so that the manual and automatic programs can be switched to each other.

The programming of the PLC adopts modular programming.

The main program calls the sub-module program manual program and automatic program and calls the more detailed sub-programs in the two subprograms.

The modular programming makes the logic of the program clearer and brings convenience to the programmer. 
The program flow chart is shown in Figure 2.

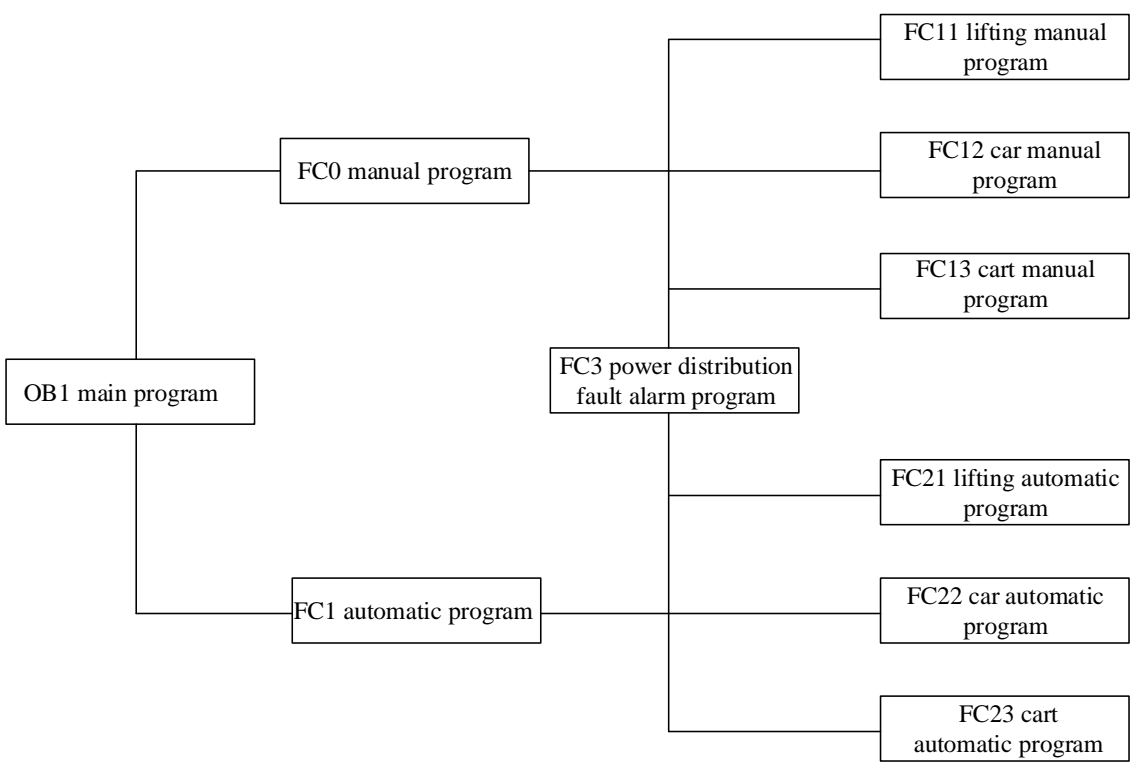

Figure 2: PLC block diagram

\section{Monitoring software design}

Visual Basic is used to develop special monitoring software for bridge cranes. It has a more userfriendly interface, powerful interface technology and high scalability for easy secondary development.

It mainly consists of two parts, the bridge crane subsystem monitoring software and the central control room monitoring software, which are installed in the crane control room industrial computer and the central control room computer respectively to provide a friendly monitoring interface to the operator.

\section{Bridge crane subsystem monitoring software}

The bridge crane subsystem monitoring program consists of three parts, interface program, control program and interface program, which are all written in Visual Basic.
An interface program is a program that exchanges data between a client program and a field controller.

Because the client program can't directly read the live signal, nor can it directly send instructions to the field controller, it is necessary to develop the program.

The key technology utilized in the interface program is the OPC interface technology.

The system shown in Figure 3 can be constructed with OPC technology, and the user can exchange data without depending on the internal structure of the device and its supplier.

If the OPC technology is not used and the drive technology is used, the user needs to develop specific interfaces and drivers for different models of different vendors, and the workload will be greatly increased. Its structure is shown in Figure 3.

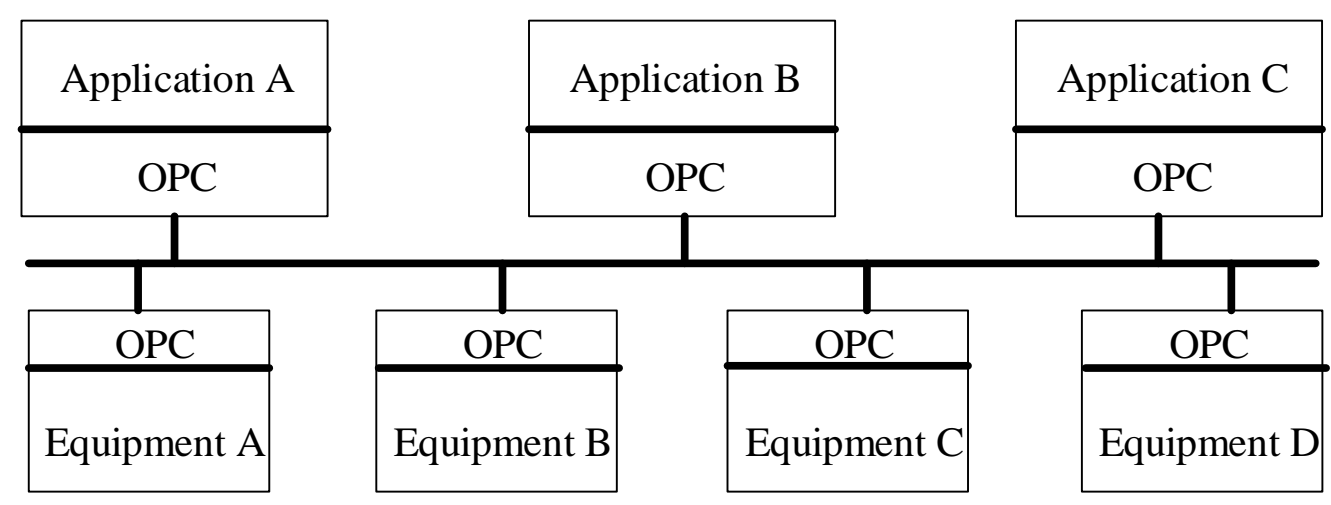

Figure 3: System connection with OPC 


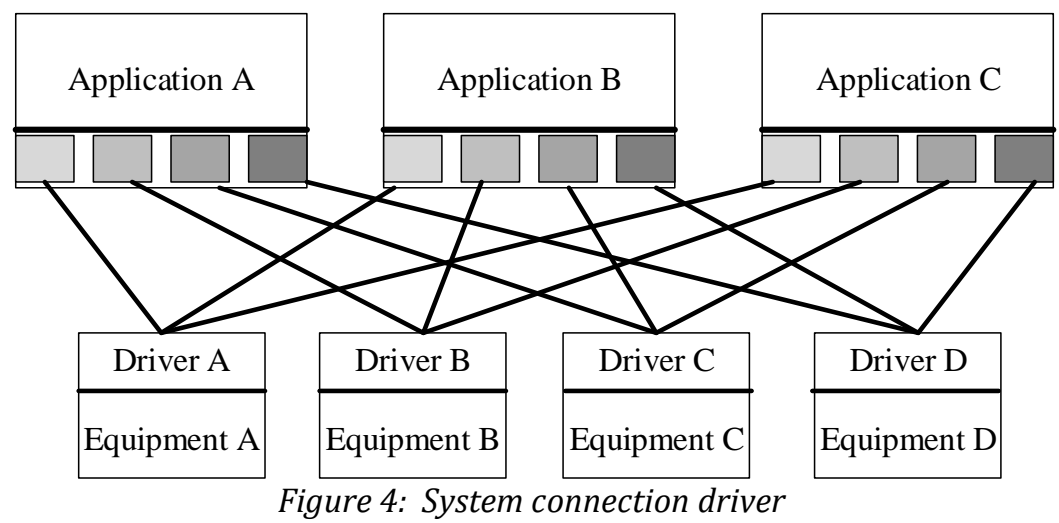

Through the comparison of the two, it can be concluded that the adoption of technology avoids spending a lot of time to express the device driver, shortens the development cycle, and makes the maintenance of the system more convenient.

\section{Central control room monitoring software}

The central control room monitoring software is mainly the editing of the configuration screen. The data received by the central control room is the data processed in the bridge crane subsystem, which is sent via the wireless data transmission station. Therefore, the data acquisition part program is not needed, and the monitoring screen is mainly edited by various controls in Visual Basic. To realize the control of the two bridge cranes in the central control room, it is only necessary to transfer the destination position of the two bridge cranes to the bridge crane subsystem. The output of all the calculation and control commands is executed by the subsystem. The central control room can remotely control the operation of two bridge cranes.

\section{Communication program design}

In the monitoring system, when the central control room system and the bridge crane subsystem are in wireless communication, the data is transmitted in a certain format. In order to ensure communication can be realized, the central control room and the crane subsystem must have a certain communication format. There is a monitoring centre and two subsystems in the monitoring system, so the system uses broadcast communication. The monitoring centre acts as the master station, and the two bridge crane subsystems act as slave stations.

The master station actively polls the slave stations and sends control information. The slave station responds after receiving the master station command and returns the slave station status data information. It can be concluded from the hardware part that the communication of the system is mainly carried out with the serial port of the computer.

In the design of the communication program, it is mainly the operation of the serial port of the computer. Both the master communication program and the slave communication program are programmed in Visual Basic.

The use of Visual Basic for serial communication programming requires four main steps as well as other object-oriented development tools: objects, properties, events, methods. The main object used in communication writing is the MSComm control. The MSComm control is a serial communication control, which saves a lot of time for programmer serial communication programming.

When using the MSComm control in Visual Basic to write the communication program of the system, it includes two parts, the main station communication program and the slave communication program. The main station initializes the serial port at the beginning of the communication, and then issues the data information or command information with the address of the No. 1 bridge crane, and then performs a short delay to receive the feedback signal from the No. 1 overhead crane. Confirm that the No. 1 bridge crane accepts the information correctly. If resending is not accepted correctly, and it is not received correctly three times in a row, the system will alert the user to a communication failure. If it is received correctly, the system will send out the data information or command information with the address of the No. 2 bridge crane and also accept the feedback signal of the No. 2 machine. If it is not received correctly, the transmission is repeated three times, and if it is accepted correctly, the recirculation is sent to the No. 1 machine. The master station uses this round-robin approach to communicate with the two slave stations.

\section{Results and Discussion}

Further reliability qualitative analysis and reliability quantitative calculation will be carried out according to the fault tree analysis method. Verify the reliability of the control system and provide a basis for system improvement. 


\subsection{Composition and function diagram of the double bridge crane control system}

It can be clearly understood from the system structure introduced in the previous chapter that the double-bridge crane control system is a typical computer control system, which mainly consists of monitoring management level, field management level, field control level and network level.

There are also signal transmission lines such as field bus.

The monitoring and management level equipment is mainly the central control room computer, which issues commands to the two bridge cranes and coordinates the operation.
The on-site control level is mainly the bridge crane subsystem computer, which is the operator station. The operator can control the bridge crane through the computer, and it is also the engineering station. The designer can develop and update the system through the computer. The field control level is mainly composed of PLC controller and remote I/O module.

The detection system is mainly composed of various sensors. The drive system is mainly the inverter and the motor, and then the signal or power line. The network level is mainly a wireless communication network, which completes the communication between the bridge crane subsystem and the central control room.

The specific structure is shown in Figure 5.

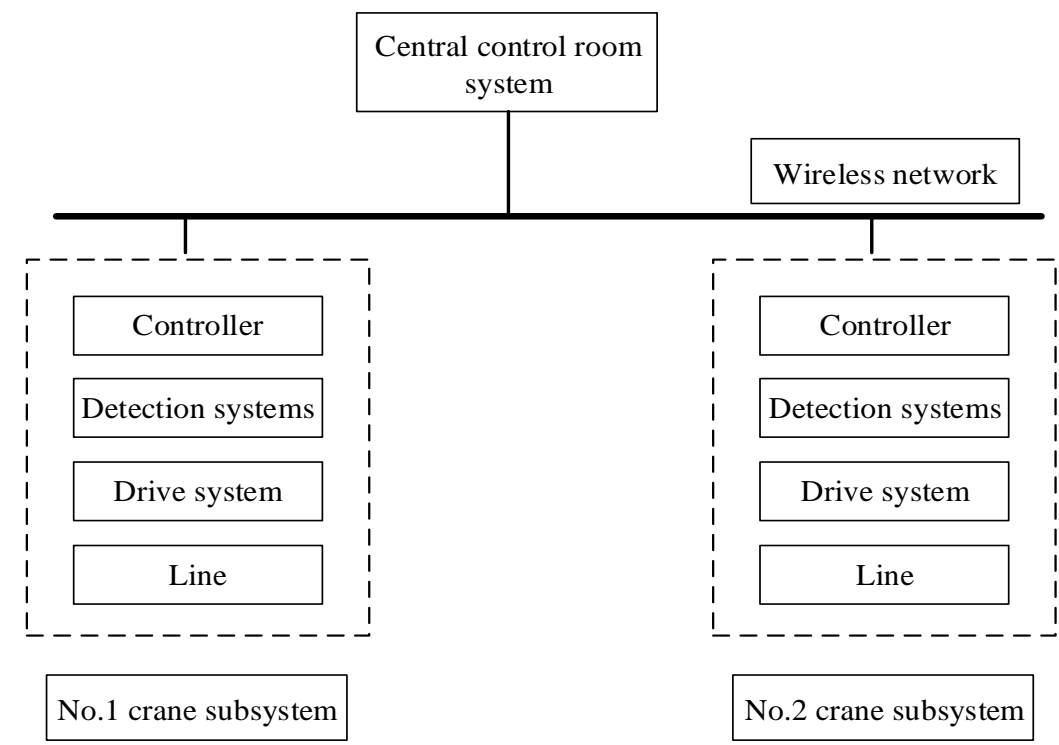

Figure 5: Block diagram of the two-machine control system

\subsection{Establishment of fault tree for control system of double bridge crane}

The design of the system is mainly the electrical control part of the bridge crane, and the analysis of the fault tree is performed for the electrical control part.

The fault analysis of the two-machine control system is shown in Figure 6.

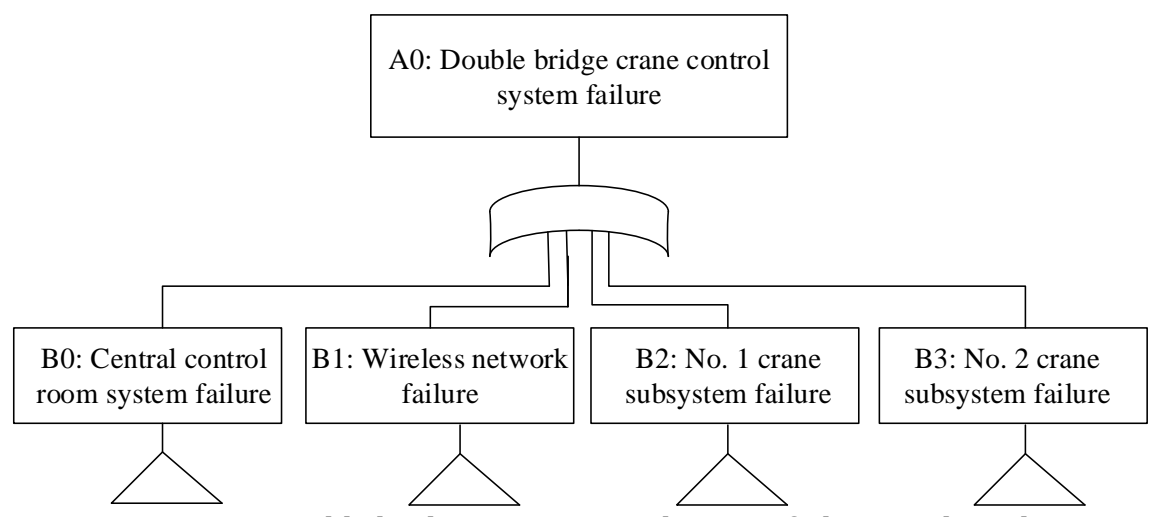

Figure 6: Double bridge crane control system failure analysis diagram

The central control room system is mainly composed of computers.
The main cause of the failure of the central control room is computer hardware failure. In order to make the fault tree not expand indefinitely, the 
two will be regarded as basic events in the analysis, and the reliability will be conservatively estimated by relevant national standards.

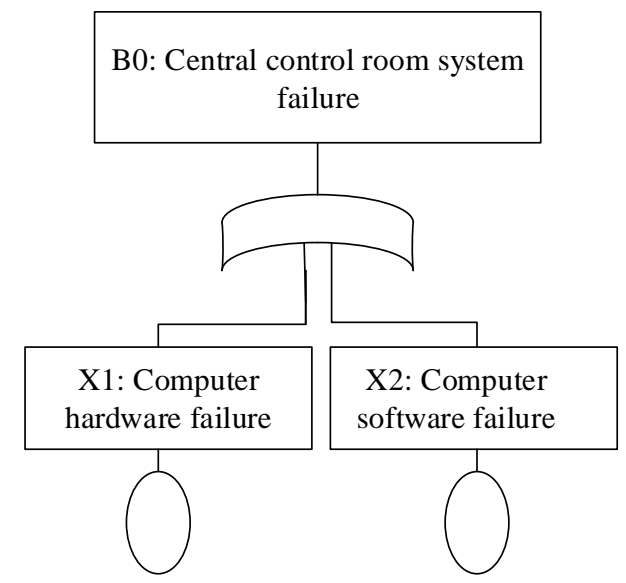

Figure 7: Central control room system failure analysis diagram

The bridge crane subsystem can be divided into an automatic part and a manual part after being modified. The automatic part and the manual part are independent of each other in the operation level, and the system only fails when both of them fail, so the relationship between the two is related.

The No. 1 crane subsystem and the No. 2 crane subsystem have the same structure, so only the No. 1 crane subsystem is analyzed here. The fault analysis diagram is shown in Figure 8.

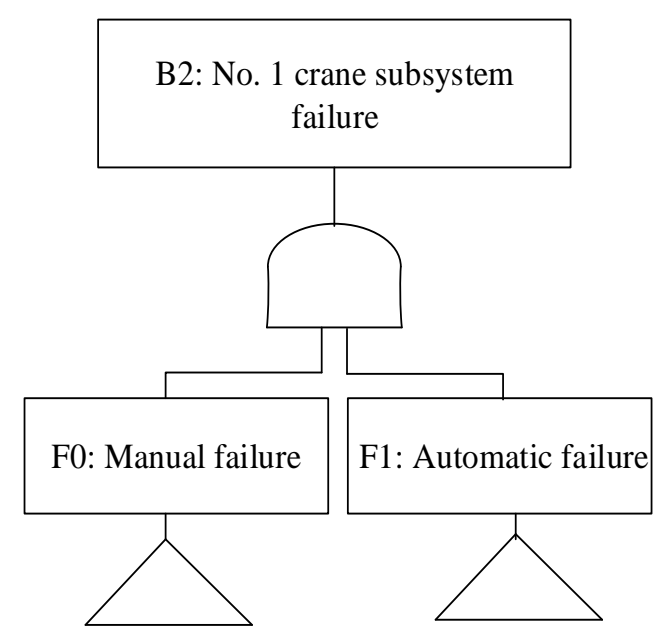

Figure 8: No. 1 crane system failure analysis diagram

The above fault tree is mainly established for the system fault tree and the partial fault tree of the No. 1 bridge crane control system.

The structure of the No. 2 crane is the same as that of the No. 1 crane, so it will not be repeated here.

\section{Conclusion}

This design is based on the original control system of the bridge crane in the finished product warehouse workshop of Tianjin Taigang Tianguan Stainless Steel Co., Ltd..

Through the research on the crane control system at home and abroad, and the analysis of the operation process of the bridge crane in the finished product warehouse, the original system is automatically modified to improve the production efficiency of the enterprise and reduce the labour intensity of the operator.

To achieve precise control of the overhead crane, the bridge crane should first be accurately positioned. In this design, three kinds of highprecision sensors such as laser range finder, bar code and encoder are used to collect the position information of the bridge crane and compare it with the destination position.

The result of the comparison is sent to the actuator by the PLC as a command.

The position is automatically operated, which saves people's labour intensity.

By using the wireless data transmission radio to realize the networking of two bridge cranes and the central control room, the central control room can monitor the running status of the two bridge cranes in real time and can send two commands to control the movement of the two bridge cranes through the central control room.

After the hardware design is completed, Microsoft Visual Basic 6.0 is used as the development platform to send out the corresponding communication program, monitoring program and interface program. Finally, the central control room remotely monitors the control mode of the two bridge cranes.

In the interface program, the OPC interface technology is used to make the data exchange between the client and the server convenient and fast, and the technology can be configured without the hardware of the system, and it can be transplanted without much change in hardware replacement, and it is convenient to expand.

In this paper, the reliability analysis of the double-bridge crane control system based on the fault tree analysis method is also carried out.

Through the establishment of the model of the system, the establishment of the fault tree, the reliability parameters of the system are finally obtained, which provides the basis for the equipment use and maintenance personnel, and the improvement suggestions, are given at the end to improve the reliability of the system. 


\section{References}

[1] Fan, X. N., \& Zhi, B. (2017). Design for a crane metallic structure based on imperialist competitive algorithm and inverse reliability strategy. Chinese Journal of Mechanical Engineering, 30(4), 1-13.

[2] Hossain, M. E. (2017). Performance analysis of diode-bridge-type non-superconducting fault current limiter in improving transient stability of dfig based variable speed wind generator. Electric Power Systems Research, 143, 782-793.

[3] Kulka, J., Mantic, M., Fedorko, G., \& Molnar, V. (2016). Failure analysis of increased rail wear of 200 tons foundry crane track. Engineering Failure Analysis, 67, 1-14.

[4] Molaei, S., \& Ganji, B. A. (2016). A new doublebridge $\mathrm{rf}$ mems switch with low actuation voltage and high isolation. Microsystem Technologies, 23(6), 1-6.

[5] Zhu, Y., Chen, B., Qin, M., \& Huang, Q. A. (2017). 2$\mathrm{d}$ micromachined thermal wind sensors-a review. IEEE Internet of Things Journal, 1(3), 216-232.

[6] Prabaharan, N., \& Palanisamy, K. (2017). Analysis of cascaded h-bridge multilevel inverter configuration with double level circuit. Iet Power Electronics, 10(9), 1023-1033.

[7] Li, X., Hu, S., Sun, C., \& Zhang, Y. F. (2017). Asymmetric-double-sided modulation for fast load transition in a semi-dual-active-bridge converter. Iet Power Electronics, 10(13), 16981704.

[8] Li, Y., Yao, Z., Fu, X. Q., Li, Z. M., Shan, F. K., \& Wang, C. (2017). The development of differential inductors using double air-bridge structure based on integrated passive device technology. SolidState Electronics, 131, 9-19.
[9] Xu, C., Dai, K., Chen, X., \& Kang, Y. (2016). Voltage droop control at point of common coupling with arm current and capacitor voltage analysis for distribution static synchronous compensator based on modular multilevel converter. Iet Power Electronics, 9(8), 1643-1653.

[10] Chen, H., Fang, Y., \& Sun, N. (2017). A swing constrained time-optimal trajectory planning strategy for double pendulum crane systems. Nonlinear Dynamics (7), 1-12.

[11] Ramli, L., Mohamed, Z., Abdullahi, A. M., Jaafar, H. I., \& Lazim, I. M. (2017). Control strategies for crane systems: A comprehensive review. Mechanical Systems and Signal Processing, 95, 123.

[12] Dragović, B., Tzannatos, E., \& Park, N. K. (2017). Simulation modelling in ports and container terminals: literature overview and analysis by research field, application area and tool. Flexible Services and Manufacturing Journal, 29(1), 4-34.

[13] Jalaludin, A. H., Shukor, M. H. A., Mardi, N. A., Sarhan, A. A. D. M., Ab Karim, M. S., Besharati, S. R., ... \& Dambatta, Y. S. (2017). Development and evaluation of the machining performance of a CNC gantry double motion machine tool in different modes. The International Journal of Advanced Manufacturing Technology, 93(1-4), 1347-1356.

[14] Aziz, N. A. A., Fumoto, A., \& Suzuki, K. (2017). Assessing human error during collecting a hydrocarbon sample of the chemical plant using therp. Journal of Fundamental and Applied Sciences, 9(7S), 255-271.

[15] Kulka, J., Mantic, M., Faltinova, E., Molnar, V., \& Fedorko, G. (2018). Failure analysis of the foundry crane to increase its working parameters. Engineering Failure Analysis, 88, 2534. 